\title{
A performatividade na dança
}

\author{
The performativity in dance
}

\author{
Karina Almeida
}

Sayonara Pereira

Karina Almeida

Pós-doutoranda na Escola de Comunicações e Artes da Universidade de São Paulo. Professora de estudo e prática corporal na Escola Superior de Artes Célia Helena

Sayonara Pereira Professora efetiva da Escola de Comunicações e Artes da Universidade de São Paulo (ECA-USP). Diretora do Laboratório de Pesquisas e Estudos em Tanz Theatralidades (Lapett) no Departamento de Artes Cênicas da ECA-USP.

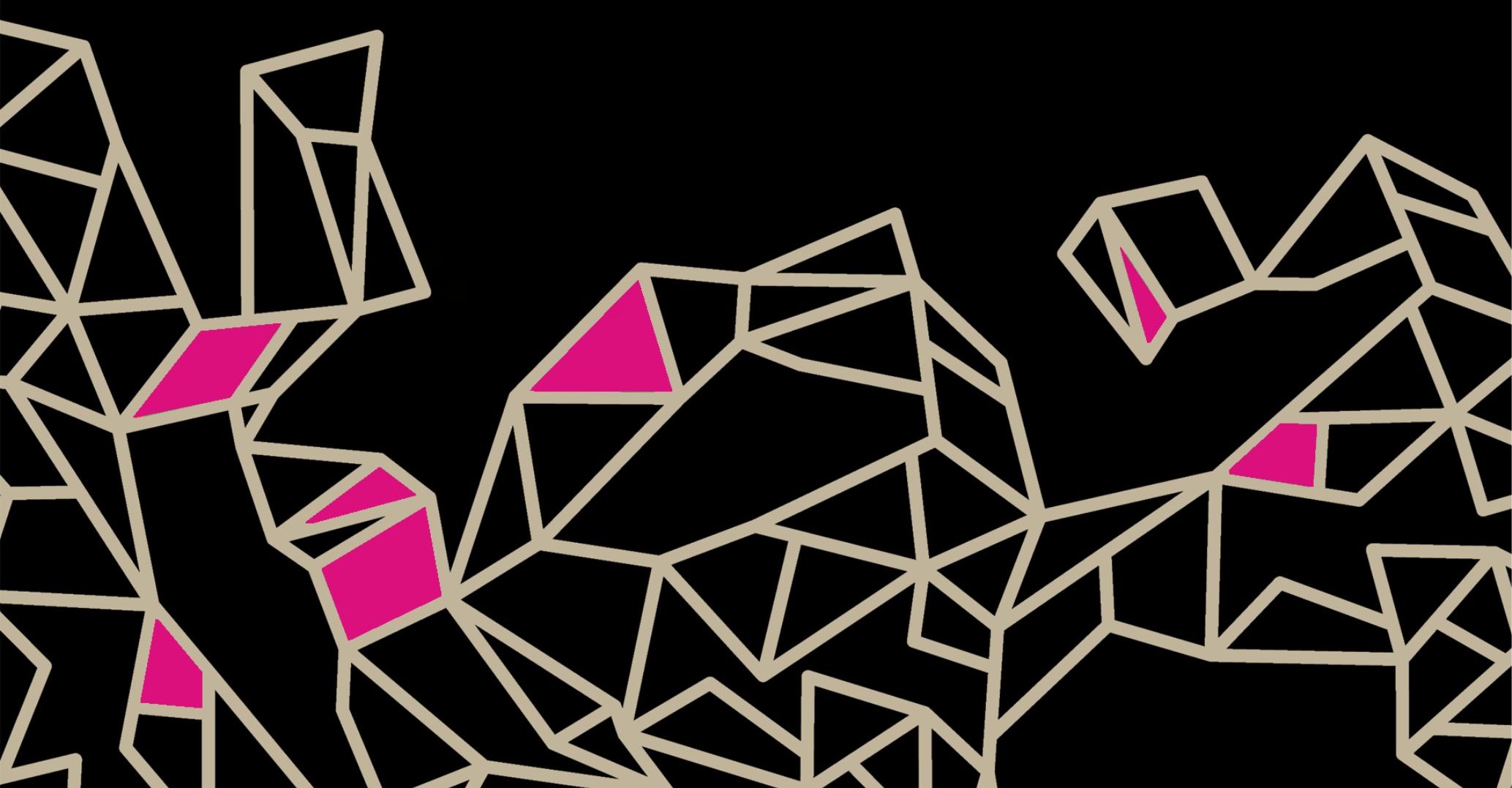




\section{Resumo}

Este artigo discute como as noções de coreografia, corporeidade e performatividade vem sendo exploradas de um modo experimental desde os anos 1960. Discute-se a noção de performativo na dança através de uma breve análise da peça What the body does not remember (1987), do coreógrafo belga Wim Vandekeybus. Do ponto de vista teórico, Féral, Schechner, Preston-Dunlop e Hantelmann são as principais referências propostas para esta discussão.

Palavras-chave: Dança, Performatividade, Coreografia, Artes da cena, Corpo.

\section{Abstract}

This paper discusses how choreography, corporeity and performativity have been experimented upon in contemporary dance since the 1960s. The meaning of "performative" in dance is presented by a brief analysis of the piece What the Body Does Not Remember (1987) by Belgian choreographer Wim Vandekeybus. From a theoretical point of view, Féral, Schechner, Preston-Dunlop and Hantelmann are the main references used for this discussion.

Keywords: Dance, Performativity, Choreography, Performings arts, Body.

A partir de 1950 é possível notar uma virada coreográfica ${ }^{1}$ no campo da dança: as fronteiras entre as artes foram borradas e o processo criativo passou a ocorrer de modo mais horizontal, investindo em práticas experimentais que intensificaram os questionamentos sobre corporeidade, efemeridade e performatividade: quais são os limites entre o que é dança e o que não é? Entre o dançarino e o público? Entre realidade e ficção? Entre obra e processo? O quanto e como a dança resiste e insiste no espaço-tempo? Quais são os lugares da dança?

Tais questionamentos foram incorporados pelos artistas da dança pós-moderna ${ }^{2}$ em suas proposições. A noção de coreografia foi ampliada à medida que novas práticas de composição surgiram, aprofundando a pesquisa

\footnotetext{
1 Ver Lepecki (2012).

2 Sobre a dança pós-moderna ver Banes (1987).
} 
sobre a potencialidade expressiva do próprio movimento e da própria corporeidade, sem depender de uma estrutura dramática ou de um tipo de narrativa linear de causa-efeito. É possível dizer que a coreografia, com seu desenho de movimento, gestos e trajetórias espaciais, longe de ser esvaziada de sentidos, passa a ser explorada como gatilho psicofísico, que "parte da execução para o desencadeamento de processos interiores" (BONFITTO, 2009, p. 39). Em outras palavras, trata-se de uma crença de que todo movimento está impregnado de processos interiores e pela experiência da corporeidade que dança. Ainda que não haja um direcionamento expressivo dado por um teor dramático, o dançarino compõe sua dança e sua expressividade tendo na mente e no corpo tudo o que ela pode significar, acionar, desvelar.

A partir dos anos 1960 a dança passa a ser construída por uma espécie de lógica cinestésica, sensorial e imagética que convida o espectador a imaginar junto, a criar associações diante de tudo que vai sendo tecido pela obra. O sentido de narrativa é expandido e o "texto espetacular" passa a ser construído por uma multiplicidade de "textos" que se manifestam pela materialidade de cada elemento que compõe a coreografia - corpos, objetos, vídeos, sons, figurinos, luzes, palavras etc. As iniciativas de vanguarda dos artistas do Judson Dance Theater ${ }^{3}$ pareciam pedir ao público que "recuperassem seus sentidos" (SONTAG, 1966, p. 14). Ao investirem na presença e fisicalidade do corpo, os artistas do Judson subvertiam totalmente as categorias tradicionais de representação e coreografia. Nesse contexto, a coreografia passa a instaurar um espaço de ação e a noção de performatividade ganha força na dança.

Se nos anos 1950 a noção de performatividade estava sendo introduzida pelo teórico da linguagem John Austin, com suas palestras da série How to do things with words (AUSTIN, 1962), os artistas da dança do mesmo período propunham, através de suas coreografias e práticas, how to do things

3 Em 1962, em Nova York, dançarinos, artistas visuais e músicos se apresentaram no saIão da igreja Judson Memorial Church, em Greenwich Village, dando origem ao Judson Dance Theater. Durante sua existência (1962-1964), esse coletivo de artistas verticalizou a ideia de que todo e qualquer movimento poderia ser dança, engendrando assim a dança pós-moderna. Entre os artistas que integraram o grupo estão: Judith Dunn, Robert Dunn, Ruth Emerson, Alex Hay, Deborah Hay, Fred Herko, David Gordon, Gretchen MacLane, Simone Forti, Robert Morris, Steve Paxton, Rudy Perez, Yvonne Rainer, Robert Rauschenberg, Carol Scothorn, Elaine Summers, Jennifer Tipton, Trisha Brown, Remy Charlip, Lucinda Childs, Carolee Schneemann, Sally Gross, Elizabeth Keen, Aileen Passloff, Albert Reid, Arlene Rothlein, Meredith Monk, entre outros. 
with bodies. Austin apresenta o termo performativo para pontuar o caráter ativo da linguagem. Exemplo de enunciado performativo dado por Austin é o "sim, eu aceito", pronunciado pelo casal na cerimônia de casamento. Conforme Hantelmann (2014), embora Austin tivesse originalmente planejado isolar certos enunciados sob a noção de performativo, ele percebeu, posteriormente, que não era possível fazer uma nítida distinção entre um enunciado constatativo (que descreve a realidade) e um performativo (que produz realidade). Cada enunciado contém aspectos constatativos e performativos e, portanto, seria redundante falar sobre a performatividade da linguagem. Para Hantelmann, o mesmo princípio pode ser aplicado às obras de arte. Por conseguinte, "não faz muito sentido falar de uma obra de arte performativa porque cada obra de arte tem uma dimensão de produção de realidade"4 (HANTELMANN, 2014, p. 1). A autora defende que

a noção de performativo em relação à arte aponta, na verdade, a uma mudança do que uma obra de arte retrata e representa para os efeitos e experiências que ela produz - ou, para seguir Austin, a partir do que ela 'diz' o que 'faz'. Em princípio, o performativo desencadeia uma mudança metodológica na forma como olhamos para qualquer obra de arte e na forma pela qual ela produz significado. Entendido desse modo, ele realmente oferece uma mudança muito interessante e desafiadora de perspectiva. Usado como rótulo para classificar um determinado grupo de obras de arte contemporânea, no entanto, não faz muito sentido 5 . (VON HANTELMANN, 2014, p. 1, grifo da autora, grifo nosso e tradução nossa)

Em seu texto The experiential turn (2014), Hantelmann argumenta que, enquanto toda obra de arte produz algum tipo de experiência estética, dos anos 1960 em diante, criar e proporcionar experiências passou a ser uma questão central da concepção artística. A discussão de Hantelmann está em sintonia com o que Fischer-Lichte (2008) chama de virada performativa (performative turn)

4 "It makes little sense to speak of a performative artwork because every artwork has a reality-producing dimension".

5 "The notion of the performative in relation to art actually points to is a shift from what an artwork depicts and represents to the effects and experiences that it produces - or, to follow Austin, from what it "says" to what it "does". In principle, the performative triggers a methodological shift in how we look at any artwork and in the way in which it produces meaning. Understood in this way, it indeed offers a very interesting and challenging change of perspective. Used as label to categorize a certain group of contemporary artworks, however, it makes little sense". 
nas artes, quando as significações emergem da própria materialidade do corpo e de sua atuação. Para discutir o que chama de virada experiencial, Hantelmann cita as instalações feitas ${ }^{6}$ por Robert Morris com suas obras minimalistas, nas quais a ideia de sentido localizado dentro do objeto - sentido que precisa ser "lido" pelo observador -, não tem mais lugar. A experiência ocorre pelo modo como a obra se relaciona com o espaço e com a corporeidade do observador. Conforme aponta a autora, a figura de Robert Morris, com suas obras e textos, foi central nessa mudança de perspectiva que passa a engajar o observador através de uma experiência corporal. $\mathrm{O}$ ato de ver a obra se desloca da visão e passa para o corpo como um todo. Com o minimalismo

foco muda de uma base interior para um efeito externo. A obra de arte não é mais vista representando um espaço interno, mental ou a consciência. Em vez disso, faz parte de um espaço externo - que compartilha com o seu observador - em que o sentido é produzido em relação a uma dada realidade situacional. Relações internas de forma e conteúdo se refugiam atrás do impacto do objeto sobre esta situação, um impacto que lança os espectadores de volta a si mesmos, em um espaço e uma situação ${ }^{7}$. (HANTELMANN, 2014, p. 4)

A dança pós-moderna se associou às proposições do minimalismo, adotando a experiência como questão central da concepção, deixando de lado a "escavação" de sentidos (SONTAG, 1966) e apostando num espaço de compartilhamento entre obra e espectador. Portanto, as articulações feitas por Hantelmann, sobre o performativo na arte estar relacionado com os efeitos e experiências que a obra produz, iluminam, também, o entendimento da manifestação da performatividade na dança.

A partir dos Performance Studies (2006) de Richard Schechner, é possível dizer que os termos performativo e performatividade são tratados como

6 Robert Morris (1931-2018) também fez parte do coletivo Judson Dance Theater. Foi casado com a bailarina Simone Forti (1935-), que também integrou o grupo. Entre as obras de Robert Morris estão, por exemplo, Untitled (Wall-Floor Slab) (1964) e Passageway (1961).

7 "The focus shifts from this interior ground to an outward effect. The artwork is no longer seen as representing a mental, internal space or consciousness. Instead it forms part of an external space - which it shares with its viewer-in which meaning is produced in relation to a given situational reality. Internal relations of form and content retreat behind the object's impact on this situation, an impact that throws viewers back on themselves, in a space and a situation". 
conceitos abertos, não sistematizáveis, que carregam consigo uma enorme variedade de significações. Segundo Schechner, a performatividade está em todo lugar, podendo ser identificada no comportamento cotidiano, nas profissões, nos diferentes tipos de mídia, nas artes e na linguagem. Uma obra performativa contém em si as propriedades de um evento, de um acontecimento, de ações que acontecem num interjogo entre o performer e o espectador. A partir dos anos 1970, a Performance Art, assim como o Happening, a Live Art, a Body Art e a Action Painting, surgem como práticas interessadas na experiência corporal, na materialidade das ações, na corporeidade dos artistas e no caráter processual da obra.

Os conceitos de performance e performatividade também permeiam o teatro que se faz hoje, conforme argumenta Josette Féral (2008). A autora propõe um outro olhar para o que foi definido por Hans-Thies Lehmann, em 1999, como teatro pós-dramático e, para tanto, apresenta a noção de teatro performativo. Féral aponta que a performatividade está no centro do funcionamento do teatro performativo, que por sua vez

procede por meio da fragmentação, paradoxo, sobreposição de significados, colagens-montagens, intertextualidade, citações, ready-mades. Encontramos a noção de desconstrução, disseminação e deslocamento de Derrida. A escrita cênica não é mais hierárquica e ordenada; ela é desconstruída e caótica, ela introduz o evento, reconhece o risco. (FÉRAL, 2008, p. 204)

As características do teatro performativo apontadas por Féral podem ser identificadas nos trabalhos do Judson Dance Theater e na dança pós-moderna. Noções como repetição, acumulação, fragmentação, montagem, colagem, justaposições radicais, estruturas/ações guiadas por tarefas, operações do acaso, correspondência entre movimento encontrado/ação cotidiana e ready-made, desconstrução da narrativa linear e de causa-efeito, tornaram-se recorrentes nas práticas coreográficas a partir dos anos 1960.

Féral nos diz ainda que o termo performer

quer seja num sentido primeiro 'de superar ou ultrapassar os limites de um padrão' ou ainda no sentido de 'se engajar num espetáculo, um jogo ou um ritual', implica ao menos em três operações, diz Schechner. 
1. ser/estar ('being'), ou seja, se comportar ('to behave');

2. fazer ('doing'). É a atividade de tudo o que existe, dos quarks aos seres humanos;

3. mostrar o que faz ('showing doing', ligado à natureza dos comportamentos humanos). Este consiste em dar-se em espetáculo, em mostrar (ou se mostrar). (FÉRAL, 2008, p. 200)

A partir de Schechner e Féral, é possível dizer que a obra performativa apresenta ações construídas por uma lógica interna que se distancia de uma ideia de representação e ficção e se aproxima do caráter pragmático da experiência vivida. Há, portanto, um foco na ação e na situação em si.

Visando investigar como ocorre a interseção entre a dança e o conceito de performatividade, as autoras Valerie Preston-Dunlop e Ana Sanchez-Coolberg, na obra Dance and the performative $(2010)^{8}$, afirmam que, enquanto todas as danças são potencialmente performativas, a distinção entre um evento performativo de dança e uma apresentação de dança é o tipo de envolvimento dos artistas com os espectadores e, em resposta, o envolvimento desses com os artistas e com a obra. Além disso, tal distinção também surge quando os coreógrafos deixam claro que as esperadas regras que norteiam uma apresentação de dança já não estão mais em operação. Diante dessas obras performativas, o espectador é convidado também a atuar, a agir e a construir junto. Tais reflexões nos permitem pensar/praticar a composição em dança em um espaço de ação e, assim, entender como a performatividade se manifesta nela.

Seguindo a linha de raciocínio apresentada por Preston-Dunlop e SanchezCoolberg, podemos identificar a noção de performatividade nos trabalhos de artistas do Judson Dance Theater, realizados a partir dos anos 1960, tais como Yvonne Rainer e Trisha Brown; dos anos 1970, como as obras de Pina Bausch; dos anos 1980, como os trabalhos de Anne Teresa de Keersmaeker e Wim Vandekeybus, dentre outros, para citar apenas alguns nesse contexto euro-americano. Por exemplo, em Trio A (1966), Yvonne Rainer trabalha com uma monótona estrutura coreográfica, opondo-se, radicalmente, ao uso de noções

8 Preston-Dunlop e Sanchez-Colberg apresentam suas reflexões a partir de uma perspectiva coreológica, que compreende os estudos desenvolvidos por Laban nomeados de Labanotation, Corêutica e Eukinética e que continuam sendo aprofundados e desdobrados por inúmeros pesquisadores. As autoras tecem reflexões articuladas com o campo da semiótica e da fenomenologia, principalmente a partir dos autores Maurice Merleau-Ponty, Umberto Eco, Stanton Garner e Bert Olen States. 
composicionais tradicionais, tais como tema, variação, contraste, clímax etc.; em Roof Piece (1971), Trisha Brown leva a dança para cima dos telhados dos prédios em Nova York, interferindo no espaço urbano, propondo uma estrutura coreográfica guiada pela repetição e trabalho com gestos cotidianos que se afastava do que era tradicionalmente concebido como dança; em Café Muller (1978), Pina Bausch explora a repetição de gestos cotidianos e movimentos abstratos de um modo inaugural, produzindo novas percepções de corpo e subjetividade, expondo diante do público os efeitos gerados pela repetição insistente nos corpos dos bailarino, criando através de sua dança-teatro um território simbólico para tratar da complexidade das relações humanas, através de um diálogo sensível com o cenário e figurinos elaborados por Rolf Borzik; em Rosas danst Rosas (1983), Anne Teresa de Keersmaeker elabora de modo particular as frases de movimento, sendo guiada pela acumulação e repetição, criando novas e complexas noções de composição, tais como chipotage ${ }^{9}$, articulando movimentos cotidianos e movimentos abstratos que evocam o universo feminino, tornando-se um marco da manifestação do minimalismo na dança ${ }^{10}$; em What the body does not remember (1987), Wim Vandekeybus investe numa estrutura coreográfica guiada pela ideia de jogo, elaborando frasses de movimento que incorporam o risco, a imprevisibilidade e o uso de materiais e objetos diversos.

Ao olhar para as rupturas promovidas por estes coreógrafos podemos dizer que a performatividade se manifesta por um tipo de composição associada à ideia de evento. Para Preston-Dunlop e Sanchez-Colberg, entender a dança como evento performativo implica considerar que a noção de processo - de obra, ensaio, pesquisa, pensamento etc. - conduz a seleção do que é relevante ou essencial para qualquer trabalho ser o trabalho. A noção de processo não apenas precede, mas também é incluída no momento da performance. Nesse sentido, a dança enquanto evento performativo questiona as linhas divisórias entre esses conceitos, de modo que o processo e suas qualidades permeiam o trabalho de diferentes formas (PRESTON-DUNLOP; SANCHEZ-COLBERG, 2010, p. 34).

9 Ver Keersmaeker e Cvejic (2012).

10 Ver Almeida (2016). 
A performatividade na dança:

aborda a questão de como um evento estabelece o seu particular 'aqui' e 'lá' e prossegue para transformá-los. Tais questões nos pedem para reconsiderar as definições tradicionais de 'quem' e 'o quê' das performances e o que faz um 'trabalho' de performance. Não existe mais uma clara divisão entre o que é intrínseco a uma performance e o que é extrínseco. Quadros referenciais que delineiam as fronteiras entre dança e não dança, entre a dança e o dançarino, entre o movimento dançado e movimento mundano, entre depois e agora, entre processo e produto, $e$ assim por diante, já não são mais, ou não necessariamente, aderidos" ${ }^{11}$. (PRESTON-DUNLOP; SANCHEZ-COLBERG, 2010, p. 37)

Tomaremos aqui como material de breve análise a obra What the body does not remember (1987), do coreógrafo belga Wim Vandekeybus, com o objetivo de apontar determinados aspectos performativos que compõem a coreografia.

Em 2013, na Bienal Sesc de Dança, pudemos assistir a What the body does not remember quando, também, participamos de um workshop ministrado por Eduardo Torroja, assistente de coreografia de Vandekeybus. Neste workshop, Torroja trabalhou duas ideias exploradas na obra, chamadas de "stomping" (pisar) e "stop and frisk" (parar e revistar). Segundo Torroja, essas ideias inspiraram a criação de jogos baseados numa lógica de ação e reação muito específica. Ele explicou que a obra é dividida em seis jogos que envolvem lidar com reações inesperadas, uma forte fisicalidade e um certo tipo de risco. Dos seis jogos, descrevemos a seguir dois que foram trabalhados no workshop.

"Stop and frisk" é o quarto jogo do espetáculo. Nele os dançarinos exploram a ideia de invadir o espaço pessoal do outro, tomando como base a ação de "parar e revistar", como em uma blitz policial. As mulheres são forçadas a abrirem suas pernas e braços e a permanecerem imóveis enquanto os homens revistam seus corpos. Elas resistem. Porém, o descontentamento e a tensão aumentam à medida que a repetição da ação se instaura. Então, pouco

11 'Address the issue of how an event establishes its particular 'here' and 'there' and proceeds to transform them. Such questions ask us to relook at traditional definitions of the 'who' and 'what' of performances and at what makes a performance 'work'. A clear divide no longer exists between what is intrinsic to a performance and what is extrinsic. Referential frames which delineate the boundaries between dance and not dance, between the dance and the dancer, between dancerly movement and mundane movement, between then and now, between process and product, and so on, are no longer, or not necessarily, adhered to"' 
a pouco, as mulheres começam a reagir de diferentes formas, ora esquivando-se do toque do outro, reagindo como por um movimento reflexo, ora dando um tapa nas mãos dos homens, ora segurando-as/aprisionando-as com força, ora tocando uma parte de seus próprios corpos, como um ato de desobediência à ordem de "permanecer imóvel", dentre outras possibilidades. A situação muda progressivamente e a ação de "parar e revistar" é transformada em uma sequência de movimentos rápidos, envolvendo o contato de um corpo com o outro, em um dueto com ritmo crescente. Durante o workshop, Torroja especificou quais seriam as ações de quem revista e de quem é revistado. As ações surgem em um processo de acumulação: primeiro, deslizar a mão sobre o corpo da pessoa revistada e, como reação, esquivar-se; segundo, escolher alguns pontos para apalpar com maior pressão e, como reação, dar um tapa; terceiro, percorrer o corpo passando por lugares onde a mão pode ser aprisionada, por exemplo, na região da axila ou entre as pernas e, como reação, prender a mão utilizando a pressão de uma parte do corpo contra a outra e, por fim, realizar um movimento aleatório de tocar uma parte do próprio corpo, como coçar o nariz, enquanto estiver sendo revistada, dentre outras possibilidades. Depois que todas as ações foram acumuladas, a dupla poderia brincar com a ordem de cada proposta. Torroja enfatizou que a intenção da ação era tão importante quanto sua execução e precisão. Nesse sentido, a coreografia é criada como roteiro de ações que funcionam como gatilho psicofísico, norteando os diferentes níveis de tensão que compõem o jogo. Pela experiência do workshop e por termos assistido à obra, entendemos que a ideia de intenção não se refere a algo que devesse ser programado mentalmente como um "estofo" para "preencher" a coreografia, mas sim a uma atenção para o "aqui e agora" do instante presente.

Com isso queremos dizer que reconhecemos em What the body does not remember uma lógica particular que emerge do encadeamento das próprias ações e da relação entre as corporeidades, criando uma espécie de tensão interna que, por sua vez, se materializa externamente. Há um conjunto de tensões que nutrem o próprio dançar e que surgem de um entrelaçamento entre o "saber" e o "não saber" articulados na ideia de jogo, que compreende uma estrutura que lida, também, com o imprevisível e com o risco.

O sexto e último jogo do espetáculo é o do pisar, chamado de "stomping". O jogo começa com dois dançarinos deitados no chão, enquanto outros dois 
passam a pisar e pular com muita força, aterrorizando os dançarinos deitados conforme pousam seus pés muito próximos a eles. Nesse jogo, (assim como no emblemático jogo de arremessar tijolos), há um risco iminente, pois os dançarinos estão realmente se esquivando do pisoteamento.

Durante o workshop, quando Torroja trabalhou o jogo "stomping", foi possível observar a incorporação do risco na cena. No entanto, o risco é incorporado por um viés paradoxal: ao mesmo tempo em que existe uma coreografia criada por uma sequência de ações precisas, que determinam um "mapa do pisoteamento" e um "mapa de fuga", o estado de tensão criado é tão grande que gera a impressão de que, a qualquer momento, o medo de ser pisoteado ou mesmo de pisotear com muita força pode dominar a situação e apagar qualquer "mapa" a ser seguido. A nosso ver, o risco se manifesta quando há um desvio de foco e atenção, mais especificamente, uma cisão entre mente e corpo. Em outras palavras, o risco se instaura à medida que, de certo modo, parece não ser possível "fazer isso, pensando naquilo". Nesse sentido, notamos que, nessa obra, a estrutura coreográfica, associada à ideia de jogo, exige dos dançarinos um estado de abertura e prontidão para lidar com o desconhecido, para agir dentro de um "aqui e agora" que compreende, também, aquilo que escapa do roteiro.

Estas reflexões nos dão fundamentos para reconhecer que a virada coreográfica dos anos 1950 e 1960 engendra uma manifestação intensa da performatividade na dança. "Intensa", pois, como vimos, enquanto todas as obras são potencialmente performativas (e, nesse sentido, podemos reconhecer traços performativos nas obras de pioneiros da história da dança como Loïe Fuller (1862$1928)^{12}$ ou ainda, nas rupturas feitas por Nijinsky (1890-1950) ${ }^{13}$ no Ballet Russes) é possível dizer que a performatividade na dança se caracteriza não pelo que ela "diz," mas pela experiência que produz. E, também, por um investimento em composições que exploram o "aqui e agora", o risco, a fragmentação, a não

12 A norte-americana Loïe Fuller fez parte da primeira geração da dança moderna. Em suas obras, tais como Serpentine dance (1886), ela criou uma dança inspirada em performances burlescas e populares, tais como a "skirt dance", explorando de forma pioneira novas tecnologias de iluminação a gás colorida. Fuller criava uma atmosfera quase hipnótica, transformando seus braços cobertos por um tecido de seda gigante em uma série de formas imensas que mudavam de cor.

13 O russo Vaslav Nijinsky foi um artista emblemático, cujas proposições coreográficas associam-se à chegada da modernidade na dança. L'Après-midi d'un Faune (1912), com música de Claude Debussy e cenário de Leon Bakst, é uma de suas obras revolucionárias feitas pela Ballets Russes. 
linearidade narrativa, umtipo de continuidade desvinculada daideia decausa-efeito, o paradoxo, a acumulação, a colagem, a processualidade, os espaços alternativos e específicos, a fronteira entre dança e não dança, a justaposição e sobreposição de camadas de movimentos, imagens, textos, dentre inúmeras possibilidades, que têm sido apropriadas e transformadas por determinados artistas, como os do Judson Dance Theater, Pina Bausch, Anne Teresa De Keersmaeker, Wim Vandekeybus, a partir de uma teia interdisciplinar desde o início do século XX.

\section{Referências bibliográficas}

ALMEIDA, K. C. Entre-territórios: a dança como catalisadora de diferentes noções de composição. 2016. Tese (Doutorado em Artes da Cena) - Instituto de Artes, Universidade Estadual de Campinas, Campinas, 2016.

AUSTIN, J. L. How to do things with words: the William James lectures delivered at Harvard University in 1955. Oxford: Clarendon, 1962.

BANES, S. Terpsichore in sneakers: post-modern dance. Middletown: Wesleyan, 1987.

BONFITTO, M. O ator-compositor: as ações físicas como eixo: de Stanislávski a Barba. São Paulo: Perspectiva, 2009.

FÉRAL, J. Por uma poética da performatividade: o teatro performativo. Revista Sala Preta, São Paulo, n. 8, p. 197-210, 2008.

FISCHER-LICHTE, E. The transformative power of performance: a new aesthetics. London: Routledge, 2008.

HANTELMANN, D. The experiential turn. In: CARPENTER, E. (ed.). On Performativity. Minneapolis: Walker Art Center, 2014. (Living Collections Catalogue, v. 1.). Disponível em: https://bit.ly/2ZxLnsB. Acesso em: 3 jul. 2020.

KEERSMAEKER, A. T.; CVEJIC, B. A choreographer's score: Fase, Rosas danst Rosas, Elena's Aria, Bartók. New Haven: Yale University Press, 2012.

LEPECKI, A. (ed.). Dance. Cambridge: MIT Press, 2012. (Whitechapel: documents of contemporary art).

PRESTON-DUNLOP, V.; SANCHEZ-COLBERG, A. Dance and the performative: a choreological perspective: Laban and beyond. London: Dance Books, 2010.

SCHECHNER, R. Performance studies: an introduction. London: Routledge, 2006. SONTAG, S. Against interpretation. In: SONTAG, S. Against interpretation and other essays. New York: [s. n.], 1966. p. 3-14.

Recebido em 18/10/2019

Aprovado em 21/05/2020

Publicado em 12/08/2020 